\title{
High-Speed Tandem Pulsed GTAW of Thin Stainless Steel Plate
}

\author{
Compared with single GTA and tandem GTA welded joints, the \\ mechanical properties of three different weld joints were studied
}

\author{
BY H. JIANG, G. QIN, C. FENG, AND X. MENG
}

\begin{abstract}
A novel high-speed welding process with tandem pulsed gas tungsten arcs, which employed two pulse arcs with a 180-deg phase to regulate the behavior of the weld pool and obtain a high-quality weld bead with low welding heat input, was proposed. The effects of pulse welding current parameters on the weld appearance were studied through a statistical design of experiment. The welding speed of a $1.2-\mathrm{mm}$-thick 304 austenite stainless steel plate can reach up to $3.0 \mathrm{~m} / \mathrm{min}$ without sacrificing weld appearance quality. The grain structure, mechanical properties, and heat input of tandem pulsed gas tungsten arc welding (GTAW-P) were analyzed and compared with those of single and tandem GTAW. Good mechanical properties of the welded joint were obtained by tandem GTAW-P. Compared with the single and tandem GTAW, the heat input of tandem GTAW-P was decreased by 17.5 and $14.5 \%$, respectively. The main arc at pulse peak obtained sufficient penetration, and the assisting arc at pulse background reduced the unnecessary heat input. When the main arc reached pulse background, the assisting arc at pulse peak heated the trailing region of the molten pool continuously to ensure reflow of the metal and suppressed the generation of weld defects.
\end{abstract}

\section{KEYWORDS}

- High-Speed Welding • Thin Stainless Steel Plate

- Tandem GTAW-P • Low Heat Input

\section{Introduction}

Gas tungsten arc welding (GTAW) is one of the most widely used welding methods due to its stable welding process, low cost, and high weld quality, especially for welding of industrial thin-walled stainless steel structures. However, considering the current-carrying capacity of the tungsten electrode is limited and the arc power is restricted, the improvement in welding productivity is directly affected. Moreover, when increasing the welding speed and welding current proportionately in single GTA high-speed welding, it is difficult to obtain a sound weld appearance because of undercut and humping defects (Ref. 1). To improve productivity, researchers worldwide have worked on high-efficiency GTAW.

Activated gas tungsten arc welding (A-GTAW) increased joint penetration, which could improve the productivity of GTAW (Refs. 2, 3). In this process, a thin layer of activated flux was deposited on the surface of a workpiece that was to be welded (Ref. 4). However, the effects of different fluxes on A-GTAW were complicated. An activated flux coating was needed before welding, which deteriorated the flexibility and efficiency of A-GTAW.

Since 1962, when it was discovered that the electromagnetic stirring effect was beneficial to refine the grain in welding (Ref. 5), many studies have been conducted using an external magnetic field to improve welding efficiency (Refs. $6-8)$. Chang et al. investigated the influence of a magnetic field on high-speed GTAW, and the welding speed was increased from 3 to $5.5 \mathrm{~m} / \mathrm{min}$ without sacrificing the weld appearance quality in a 0.5 -mm-thick $316 \mathrm{~L}$ austenite stainless steel pipe (Ref. 9). In this process, the magnetic field suppressed the backward dragging of the arc and improved the arc stiffness in high-speed welding.

In 1980, Steen et al. observed that the arc root was constricted by the presence of laser plasma from the weld fusion zones. There was an increase in welding speed and weld penetration by adding an arc to a laser (Ref. 10). For the welding of a 3-mm-thick 304 austenite stainless steel plate, sound weld appearance and excellent mechanical properties of the joint were obtained by laser GTAW and the welding speed could reach $3 \mathrm{~m} / \mathrm{min}$ (Ref. 11). Furthermore, the laser-GTA hybrid welding process was successfully applied to the assembly of automotive bodies and parts (Ref. 12). In this process, a laser beam and welding arc were coupled to achieve an increase in welding efficiency (Ref. 13).

Twin electrode GTAW, which employs two electrodes within a single torch, was developed by Japanese researchers in recent years. A bigger hybrid arc was generated by the twin electrode, and its shape could be adjusted by pulse current. This method was successfully applied to the joints at different welding positions in the inner tank of a large PC LNG storage tank, and it improved the welding efficiency (Ref. 14). A deeper surface depression would be induced by 

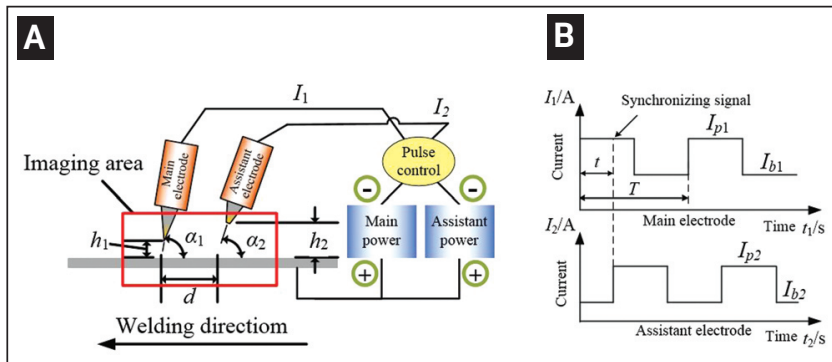

Fig. 1 - Schematic of tandem GTAW-P welding: A - Experimental configuration; $B$ - currents of the main and assisting electrodes.

the higher arc pressure, which might initiate the occurrence of undercut and humping defects (Ref. 15). However, in twin-electrode GTAW, the arc pressure was much lower than that of conventional GTA with similar welding heat input; this was the main reason for its high efficiency in GTAW, as showed by the work of Leng et al. (Ref. 16).

High-speed tandem gas tungsten arc welding (tandem GTAW) was proposed in Qin's previous work (Ref. 17). Two electrodes were employed: a main GTA with a higher welding current and better stiffness aimed to attain sufficient penetration, and an assisting GTA with a lower welding current, which heated the trailing region of the molten pool formed by the main arc to push the molten metal forward, thereby suppressing the formation of undercut and humping defects. The tandem GTAW process was successfully applied to a 409L ferritic stainless steel pipe, and the welding speed could reach up to $5.1 \mathrm{~m} / \mathrm{min}$ without occurrence of undercut and humping defects under the condition of similar heat input to that of single GTAW (Ref. 18).

To further reduce the welding heat input, a high-speed tandem pulse gas tungsten arc welding (tandem GTAW-P) process is proposed in this paper based on the previous tandem GTAW with constant current. The influences of welding parameters on weld appearance defects were systematically studied through a statistical design of experiment (DOE). The welding heat input, and the microstructure and mechanical properties of the weld were tested and analyzed, and these properties were compared with the tandem and single GTA welds. The tandem GTAW-P mechanism was also discussed by analyzing the arc interaction and molten pool configuration.

\section{Experimental Details}

\section{Principle of Tandem GTAW-P}

To further reduce the welding heat input and regulate the molten pool behavior, two pulsed welding currents were used in tandem GTAW-P instead of a constant direct current. A phase difference of 180 deg was set between the two welding

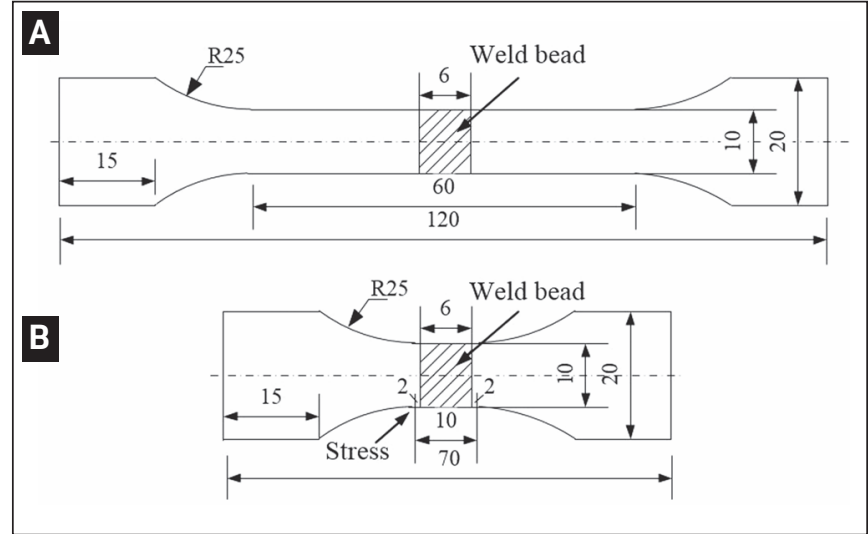

Fig. 2 - Geometry of tensile test specimens: A - Standard specimen; $B$ - nonstandard specimen.

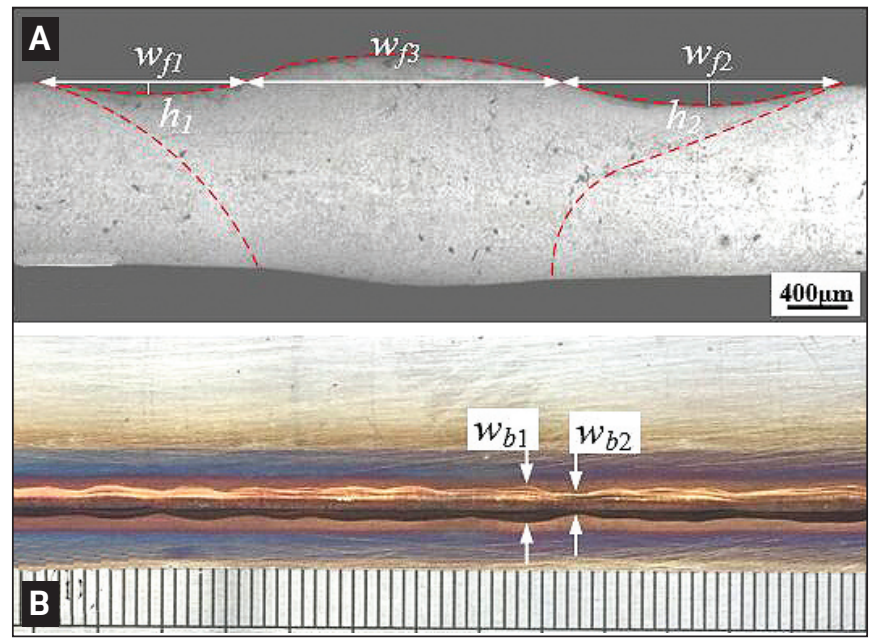

Fig. 3 - Geometry size of weld appearance: A - Undercut and weld front width; $B$ - weld back width.

currents. The schematic of the high-speed tandem GTAW-P process is illustrated in Fig. 1, where separate pulse direct current power sources were used. When the main arc current was at the pulse peak stage, the assisting arc current was at its background stage. The main arc aimed to obtain sufficient penetration. Meanwhile, the assisting arc kept burning at a lower current level, which reduced the unnecessary welding heat input. When the main arc current was at its background stage, the assisting arc current reached the pulse peak stage. The assisting arc heated the trailing region of the molten pool continuously to prolong the existence time of the molten met$\mathrm{al}$ and to ensure that the metal had sufficient time to reflow. Furthermore, the assisting arc produced a larger forward driving force, which prevented the molten metal from accumulating at the tail of the molten pool and promoted the molten metal flow to the front region of the weld pool.

Table 1- Nominal Chemical Compositions of 304 Austenite Stainless Steel (wt-\%)

\begin{tabular}{cccccccc}
$\mathrm{C}$ & $\mathrm{Mn}$ & $\mathrm{Cr}$ & $\mathrm{Ni}$ & $\mathrm{S}$ & $\mathrm{Si}$ & $\mathrm{P}$ & $\mathrm{Fe}$ \\
\hline 0.08 & 2.00 & $18.0-20.0$ & $8.0-10.5$ & 0.03 & 1.00 & Bal. & 0.035 \\
\hline
\end{tabular}


$\mathbf{A}$

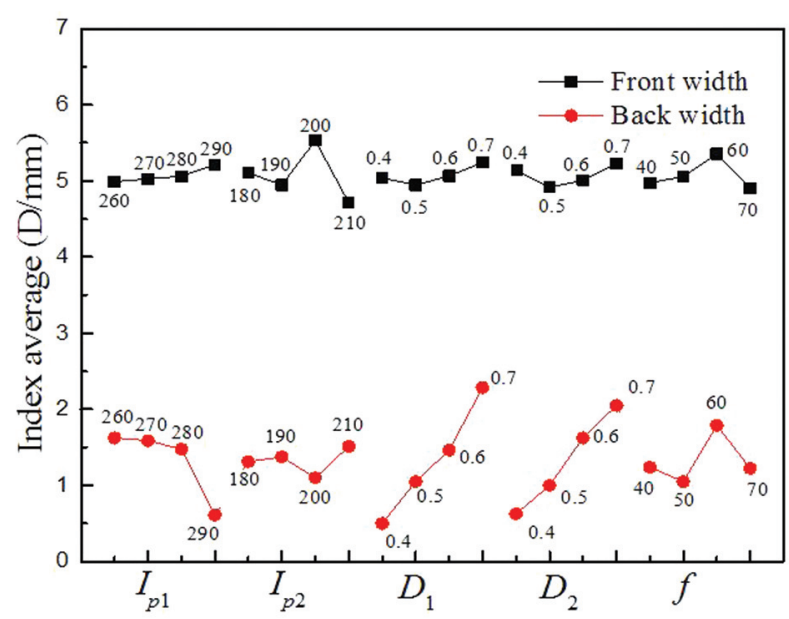

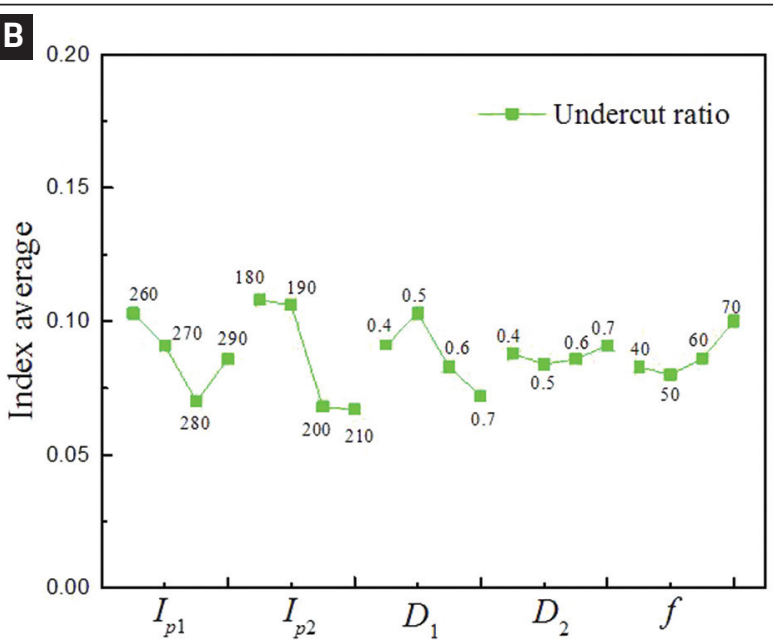

Fig. 4 - Influences of different parameters on weld appearance: A - Weld front width and weld back width; B - depth/width ratio of undercut.

\section{Materials and Welding Procedure}

The material used in the experiment was a 304 austenite stainless steel plate with dimensions of $300 \times 60 \times 1.2 \mathrm{~mm}$. Its nominal chemical composition is presented in Table 1.

Two pulse direct current welding power sources of 400-A capacity were supplied to the high-speed tandem GTAW-P experimental system and the butt joint configuration was carried out. The pulse coordination control function between the two welding power sources was conducted by analog circuit control. The assisting welding power could receive a synchronizing signal from the main welding power, which cannot only synchronize the amplitudes of the assisting pulse current and main pulse current, but also make the assisting pulse current start at its peak stage, as shown in Fig. 1B. Therefore, the phase difference could be adjusted arbitrarily by controlling the transmission time of the syn-

Table 2 - Welding Parameter Constants of Tandem GTAW-P

\begin{tabular}{|c|c|c|c|}
\hline Welding Parameters & Main & & Assisting \\
\hline Electrode angles $(\alpha)$ & $84 \mathrm{deg}$ & & $75 \mathrm{deg}$ \\
\hline Electrode heights (h) & $1.2 \mathrm{~mm}$ & & $2.5 \mathrm{~mm}$ \\
\hline Interelectrode distance (d) & & $16 \mathrm{~mm}$ & \\
\hline $\begin{array}{l}\text { Background current }\left(I_{b}\right) \\
\text { Phase difference }(\vartheta)\end{array}$ & & $\begin{array}{c}100 \mathrm{~A} \\
180 \mathrm{deg}\end{array}$ & \\
\hline Welding speed $(v)$ & & $3 \mathrm{~m} / \mathrm{min}$ & \\
\hline
\end{tabular}

chronizing signal from the main welding power. The phase difference $\vartheta$ can be expressed as the following:

$$
\theta=\mathrm{t} / \mathrm{r} \times 360 \mathrm{deg}
$$

where $t$ is the transmission time of synchronizing signal from the main welding power, and $T$ is the period of pulse cycle of the welding currents.

The orientation of the welding torches was corrected by a specially designed fixture, which could adjust the angle and height of the tungsten electrodes and the interelectrode distance. Pure argon was used as a shielding gas at the front and reverse side of the weld bead, and the flow rates of pure argon from the main torch, assisting torch, and reverse side of the weld bead were 10,10, and $15 \mathrm{~L} / \mathrm{min}$, respectively. The diameter of the two electrodes was $3.2 \mathrm{~mm}$, and the extensile lengths of the main and assisting electrodes were 6.5 and $5.0 \mathrm{~mm}$, respectively. A conic electrode tip with a 30-deg tip angle was used for the main electrode and single GTA electrode, and a truncated electrode tip with a 60-deg tip angle was used for the assisting electrode.

Although many parameters are involved in tandem GTAW-P, some parameters could be regarded as constants after being determined. The height $(h)$ and angle $(\alpha)$ of the tungsten electrode, interelectrode distance $(d)$, phase difference $(\vartheta)$, and so on, remained the same as those employed in the experimental analysis of the single-factor variable in a previous work, as listed in Table 2 (Ref. 17).

Table 3 - Welding Parameters and Their Levels in the Orthogonal Experiment

\begin{tabular}{cccccc} 
Parameters & Unit & \multicolumn{3}{c}{ Levels of Factors } & 3 \\
& & 1 & 2 & 280 & 4 \\
\hline$p_{1}$ & $\mathrm{~A}$ & 260 & 270 & 200 & 290 \\
$I p_{2}$ & $\mathrm{~A}$ & 180 & 190 & 0.6 & 210 \\
$D_{1}$ & - & 0.4 & 0.5 & 0.6 & 0.7 \\
$D_{2}$ & - & 0.4 & 0.5 & 60 & 0.7 \\
$f$ & $\mathrm{~Hz}$ & 40 & 50 & 70
\end{tabular}


The influence on weld appearance of other parameters produced by the pulse current, including main arc pulse peak current $\left(I_{p 1}\right)$, assisting arc pulse peak current $\left(I_{p 2}\right)$, main arc duty cycle $\left(D_{1}\right)$, assisting arc duty cycle $\left(D_{2}\right)$, and pulse frequency $(f)$, were studied by an orthogonal experiment of five factors and four levels using an $\mathrm{L}_{16}\left(4^{5}\right)$ orthogonal array. The pulse frequency values of the two welding power sources were maintained equal in tandem GTAW-P. The welding parameters and their levels are listed in Table 3.

\section{Analysis Methods}

The microstructure of joints welded by traditional single GTA, tandem GTA, and tandem GTA-P welding were analyzed using an Olympus GX-51 optical microscope, for which the cross section of the specimens were prepared according to the standard metallographic procedure and etched with a solution of hydrochloric acid, nitric acid, and distilled water in proportion of 3:1:1. The Vickers microhardness distribution on the cross section of the specimen along the centerline was measured with an internal spacing of $0.5 \mathrm{~mm}$ under a 1-kgf load dwelled for $10 \mathrm{~s}$.

For stainless steel joints, the plastic and strength properties of the welds have important influence on the quality of the secondarily formed structural parts. The standard tensile test specimens were prepared in accordance with China's National Standard of GB/T 228.1-2010, as shown in Fig. 2A. However, part of the base metal is included in the standard specimen, which has a longer parallel length than its weld width. Further, it is difficult to reflect the real values of tensile strength and elongation of the welds exactly if the fracture position occurs in the base material. Thus, to detect the mechanical properties of the welded joints, nonstandard tensile specimens, which had a little longer parallel length than the weld width, were

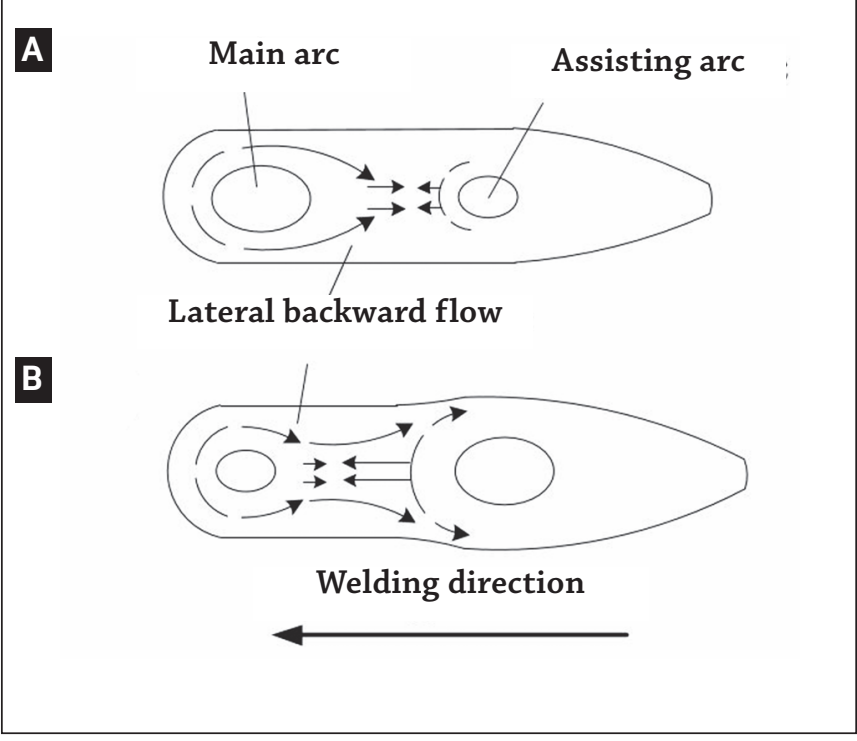

Fig. 5 - Molten pool behavior on the surface of a weld: $A-$ Main arc current at peak stage and assisting arc current at background stage; $B$ - main arc current at background stage and assisting arc current at peak stage.

prepared as shown in Fig. 2B. The tensile test was applied with a constant crosshead speed of $50 \mathrm{~mm} / \mathrm{min}$ to simulate the process of plastic deformation in the experiment of steel pipe hydraulic bulging. In addition, measured after welding, the width of the welded joint was approximately $6 \mathrm{~mm}$, and $2 \mathrm{~mm}$ width was extended along both sides of weld bead. This method aimed to reduce the influence of stress concentration, which was possibly produced by thermal deformation on the weld toe during welding, as shown in Fig. 2B.
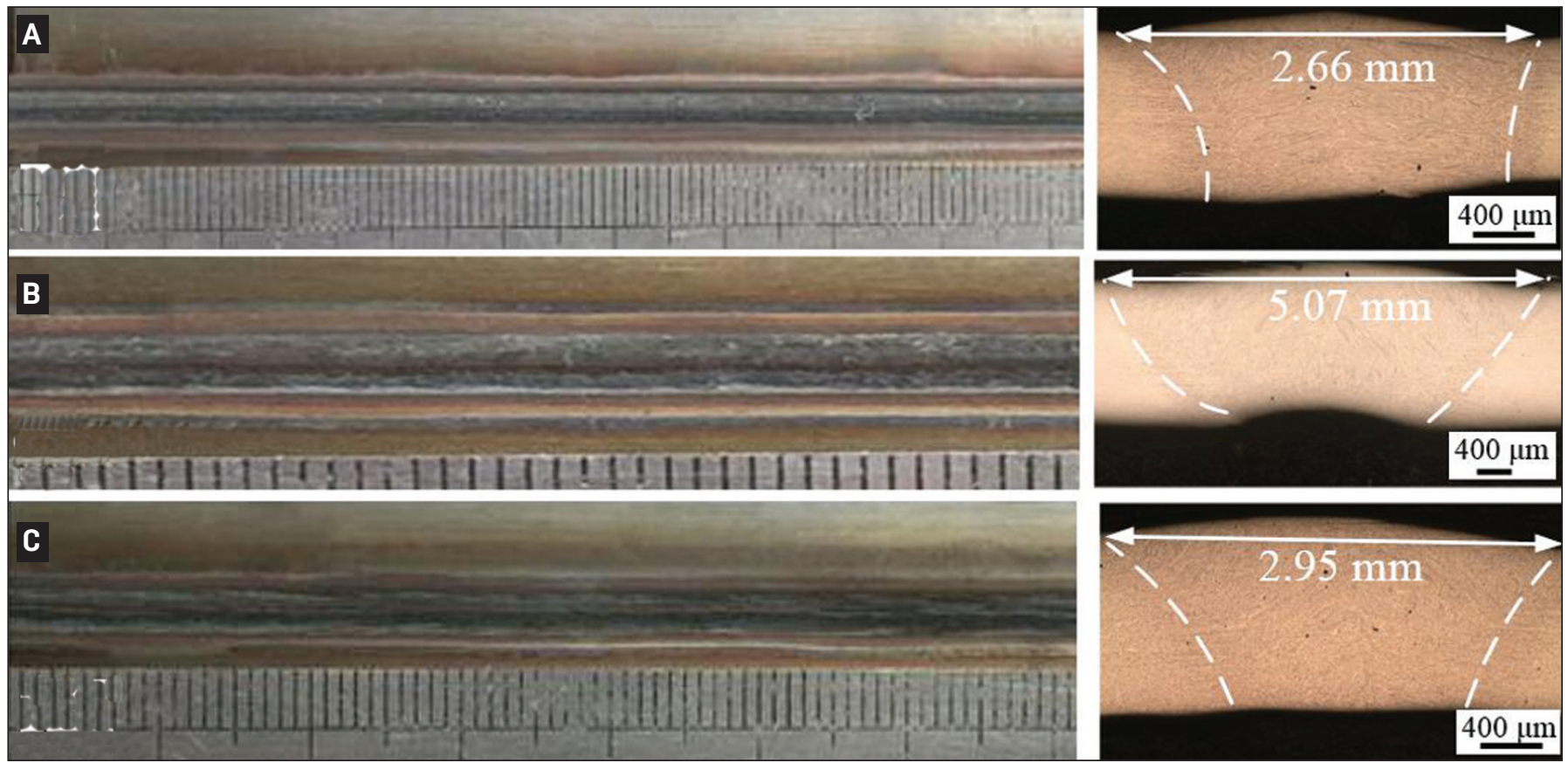

Fig. 6 - Appearance of the front and cross section of the weld: $A-$ Single GTA, $I=145 \mathrm{~A}, v=1.2 \mathrm{~m} / \mathrm{min} ; \mathrm{B}-$ tandem GTA, $I_{l}=230$ $A, I_{2}=112 \mathrm{~A}, v=3 \mathrm{~m} / \mathrm{min} ; C$ - tandem GTA-P, $I_{p l}=270 \mathrm{~A}, I_{p 2}=200 \mathrm{~A}, I_{b l}=I_{b 2}=100 \mathrm{~A}, v=3 \mathrm{~m} / \mathrm{min}$. 
Table 4-Results of Orthogonal Experiment and Range Analysis

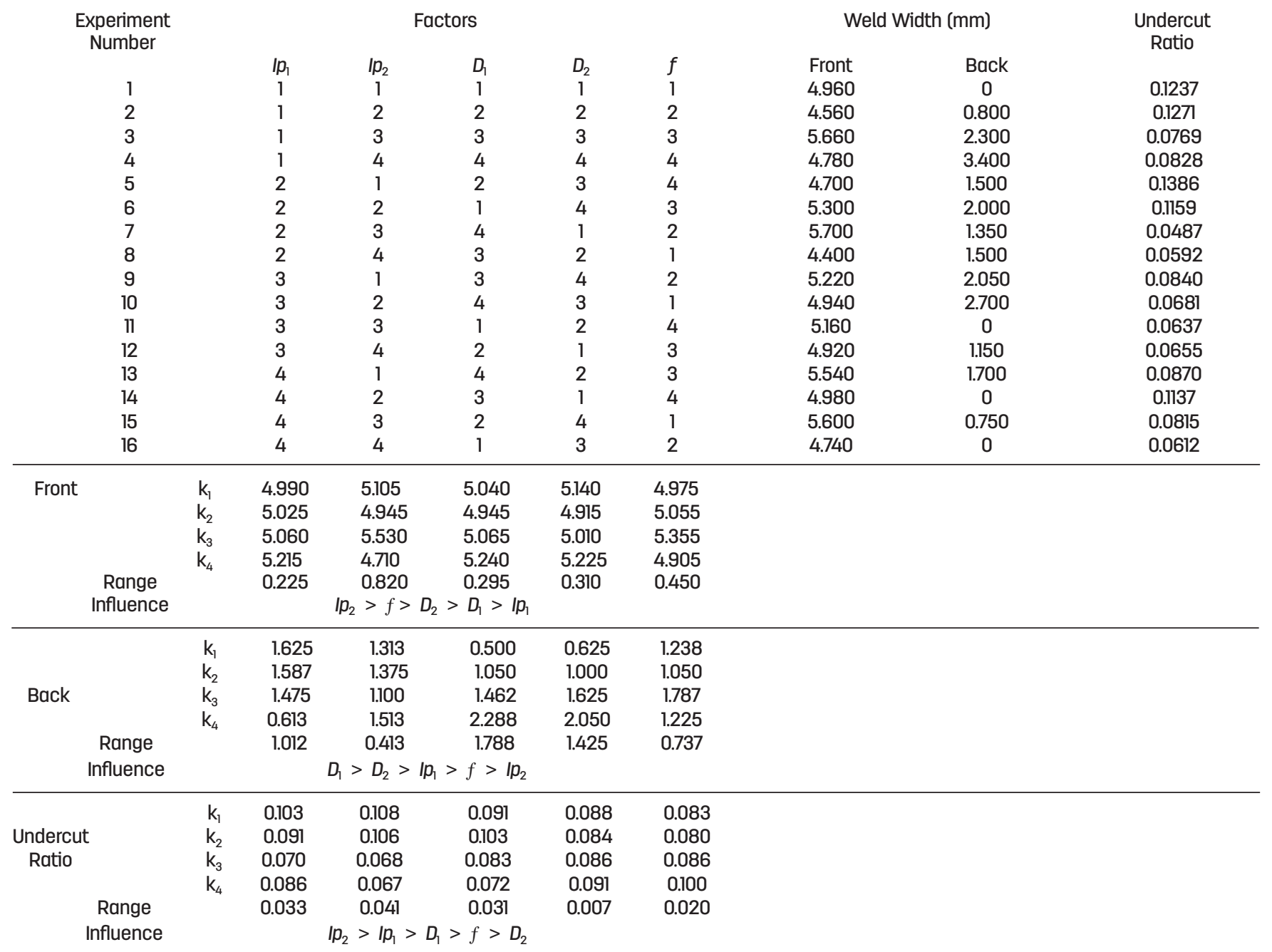

To calculate the welding heat input in different welding processes, the electrical parameters were detected by the data acquisition card USB2831 produced by ART technology with a sample rate of $120 \mathrm{kHz}$. Meanwhile, the welding arc was captured by a Basler acA2000 high-speed camera with a recording rate of $165 \mathrm{fps}$. The camera was placed perpendicular to the welding direction and parallel to the top of the welding workpiece.

\section{Experimental Results}

\section{Effects of Pulse Welding Current Parameters}

An orthogonal experiment of five factors and four levels was used to investigate the degree of influence of the pulse welding current parameters on weld appearance. As the defect of undercut was observed in the experiments, the weld front width $\left(w_{f 1}+w_{f 2}+w_{f 3}\right)$, weld back width $\left(\left(w_{b 1}+w_{b 2}\right) / 2\right)$, and depth/width ratio of undercut $\left(\left(\mathrm{h}_{1}+\mathrm{h}_{2}\right) /\left(\mathrm{w}_{\mathrm{f1}}+\mathrm{w}_{\mathrm{f} 2}\right)\right)$ were chosen as the quality characteristics, as illustrated in Fig. 3 . The size of the undercut defect could be measured from the cross section of the weld.

The results of the orthogonal experiment are presented in Table 4, and the trend graph of the factors on welding appearance is plotted in Fig. 4. As most welds were completely penetrated in the orthogonal experiment, the use of the weld back width was aimed to reflect the ability of penetration for the different factors.

For the weld front width, the pulse peak current of the assisting arc was the most influential factor, followed by pulse frequency, whereas main arc pulse peak current was the least influential.

Figure 4A shows the weld front width first increased with a higher main arc pulse peak current, which would generate much higher welding heat input and much stronger acquiring ability of weld penetration and weld width. The assisting arc pulse peak current played an important role on the weld front width. The stiffness of the assisting arc was poor, which was mainly caused by the electromagnetic attraction (Ref. 19). Liu suggested that the mean voltage of the arc cur- 

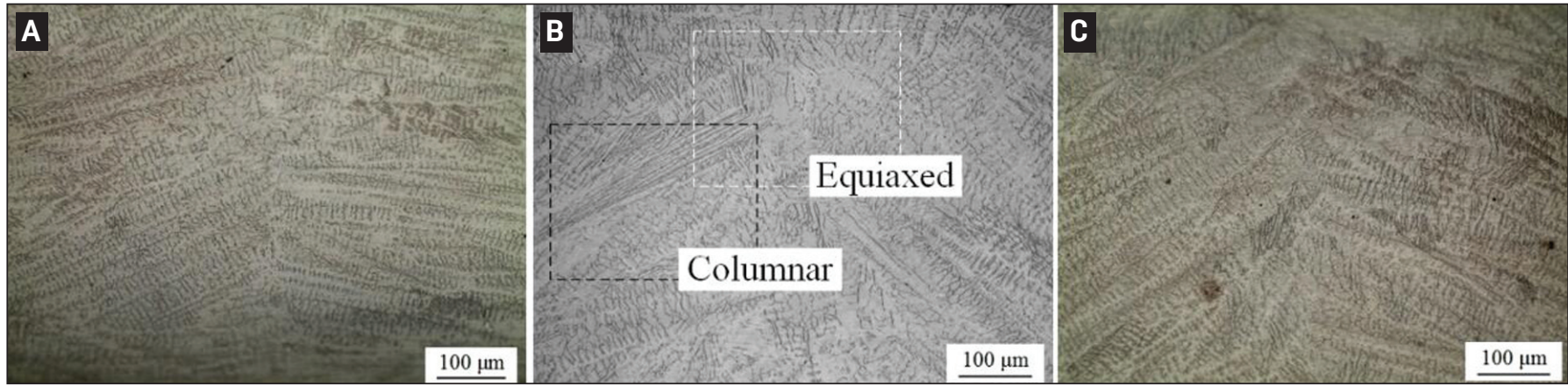

Fig. 7 - Comparison of microstructure morphology between single GTA, tandem GTA, and tandem GTA-P welds: A - Single GTA; B tandem GTA; $\mathrm{C}$ - tandem GTA-P.

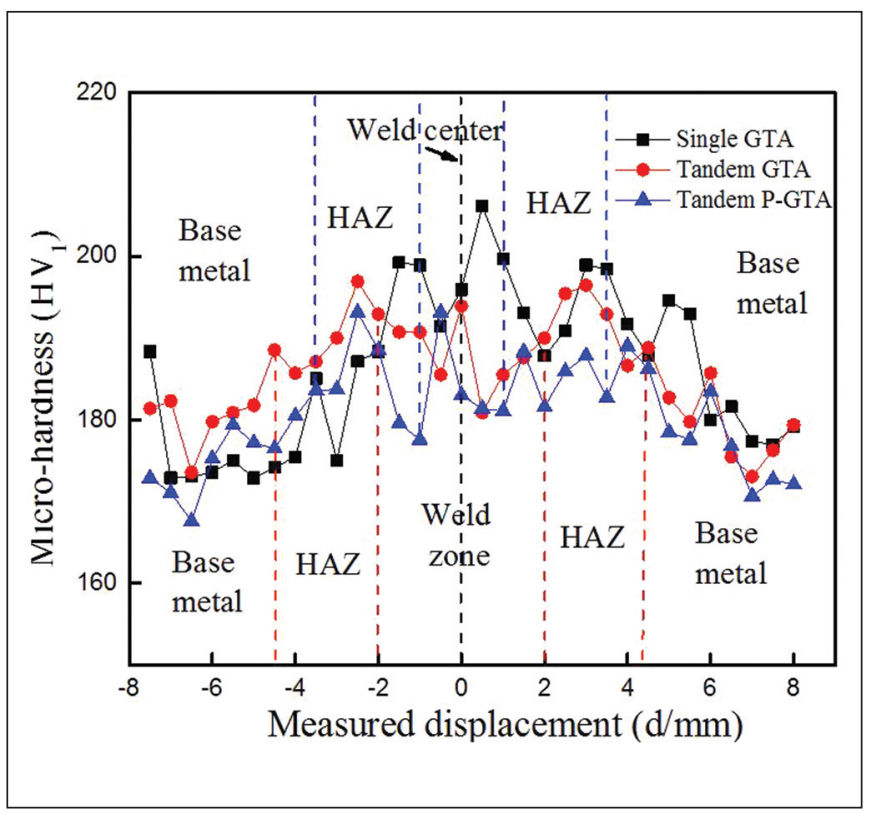

Fig. 8 - Microhardness distribution in single GTA, tandem GTA, and tandem GTA-P joints. rent would be reduced by the higher pulse frequency in GTAW-P, and the arc would shrink, which aims to keep the least arc heat input (Refs. 20, 21). In tandem GTAW-P, both arcs shrunk with a higher pulse frequency, and the weld front width decreased significantly when it was more than $60 \mathrm{~Hz}$.

For the weld penetration (back width), the main arc duty cycle was the most influential factor, whereas the influences of the pulse frequency and assisting arc pulse peak current were relatively smaller than those of the other factors. The explanation was that the welding heat input was increased by a higher arc duty cycle, and the peak current with longer pulse time would promote the heat transfer from the arc into the metal pool, especially for the main arc, which had a considerably higher pulse peak current. A higher pulse peak current greatly improved the arc forces, and weld penetration would be increased in single GTAW (Refs. 22, 23). However, the weld penetration decreased with the increase in the main arc pulse peak current in tandem GTAW-P, as shown in Fig. 4A. This feature can be explained by the interaction between the two arcs. With the increase in main arc pulse peak current, the assisting arc stiffness at the background stage became poorer and its deflection increased because of the increase in electromagnetic attraction between the two arcs (Refs. 24-26). This deflection would significantly decrease

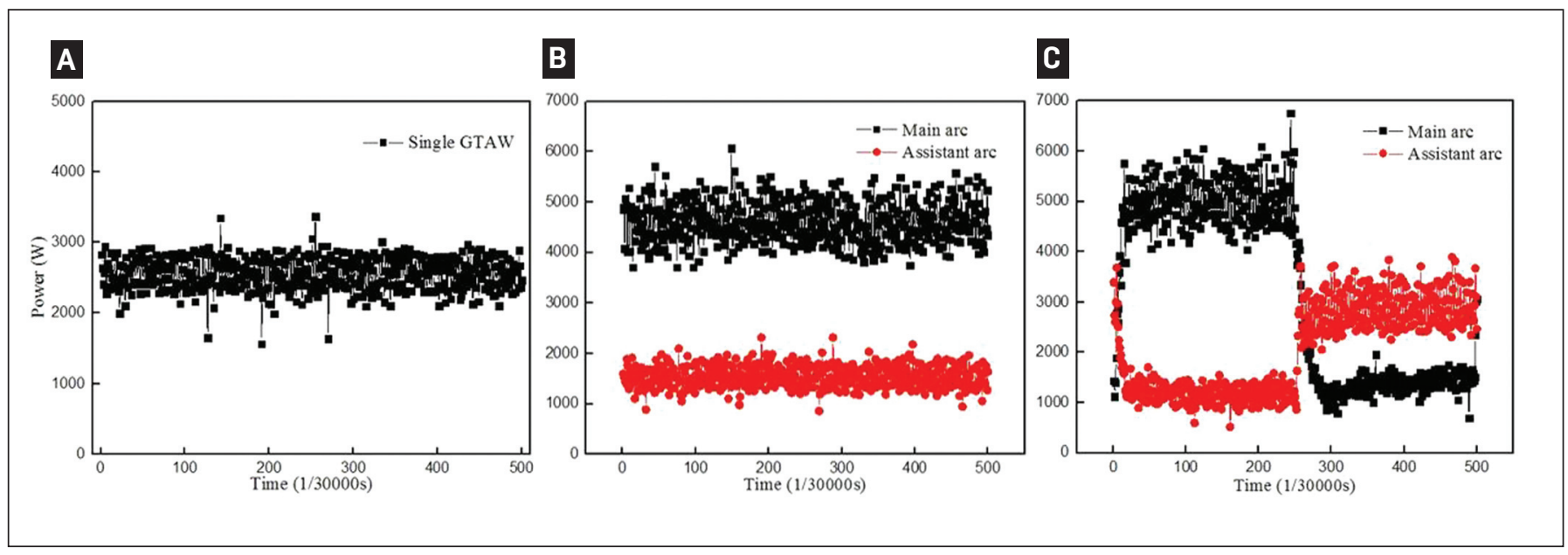

Fig. 9 - Comparison of welding power within a pulse period (1/60 s): A - Single GTAW; B - tandem GTA; C - tandem GTA-P. 


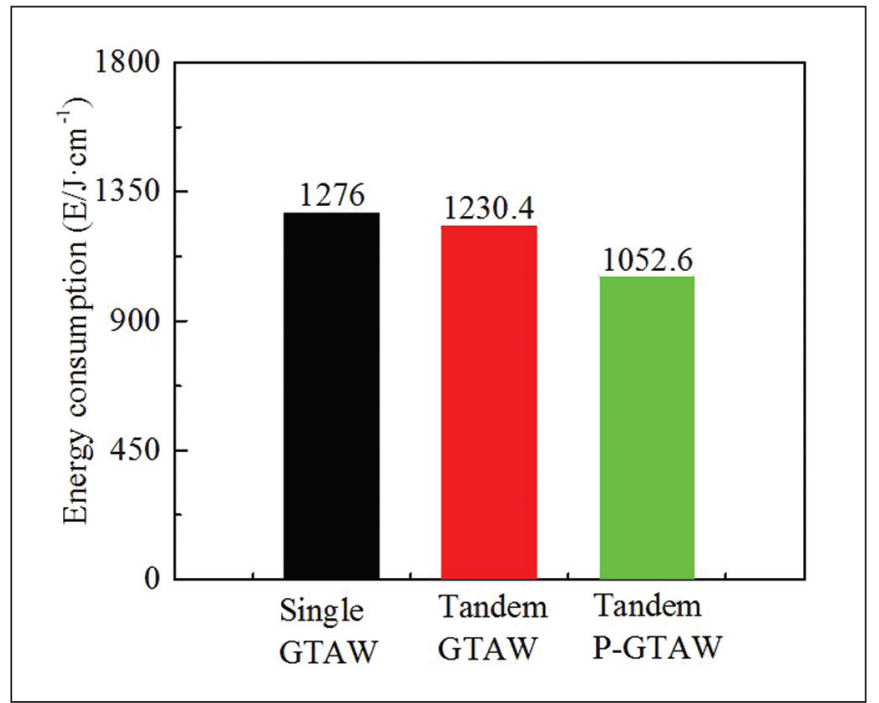

Fig. 10 - Comparison of welding energy consumption of different welding processes. the pressure and heat input of the assisting arc (Ref. 27). Furthermore, the main arc stiffness was similarly influenced by the assisting arc under the effect of electromagnetic attraction, which would weaken the penetration ability of the main pulse peak arc.

For the depth/width ratio of undercut, the pulse peak currents played an important role in tandem GTAW-P. With the higher pulse peak currents, the two pulse arcs would deflect severely with the effect of higher electromagnetic attraction. A complicated molten pool flow would be caused by arc deflection, and the weld appearance quality would eventually be easily affected. Table 4 shows the assisting arc pulse peak current is the most influential factor, followed by the main arc peak current, while the assisting arc duty cycle is the least influential. The weld appearance quality increased with the increase in main arc pulse peak current, and then slightly deteriorated when it was too high. A higher assisting arc pulse peak current tended to obtain lower depth/width ratio of undercut, which would optimize the quality of the weld appearance, as shown in Fig. 4B.

Table 5 - Comparison of Microstructure between Single GTA, Tandem GTA, and Tandem P-GTA Joints

Weld Zone

HAZ

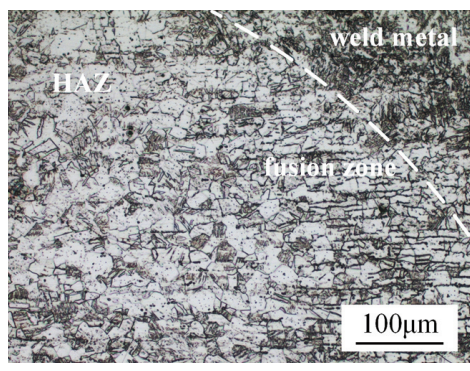

Single GTAW

$I=145 \mathrm{~A}, v=1.2 \mathrm{~m} / \mathrm{min}$

Tandem GTAW

$l_{1}=230 \mathrm{~A}, l_{2}=112 \mathrm{~A}$,

$v=3 \mathrm{~m} / \mathrm{min}$
Tandem P-GTAW

$I p_{1}=270 \mathrm{~A}, I p_{2}=200 \mathrm{~A}$,

$I b_{1}=I b_{2}=100 \mathrm{~A}$,

$v=3 \mathrm{~m} / \mathrm{min}$
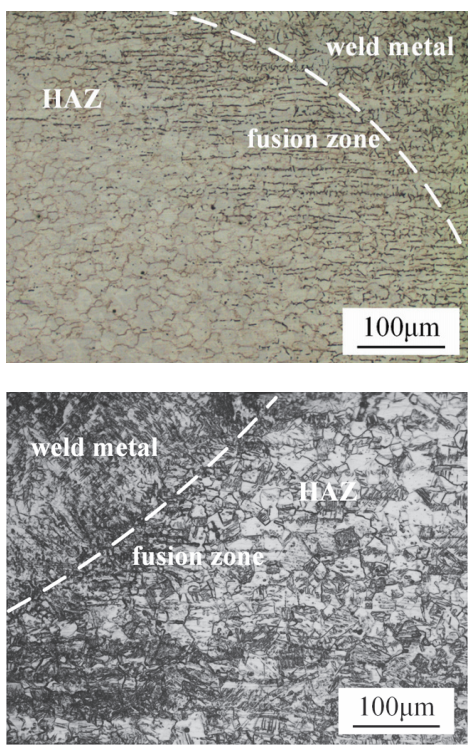
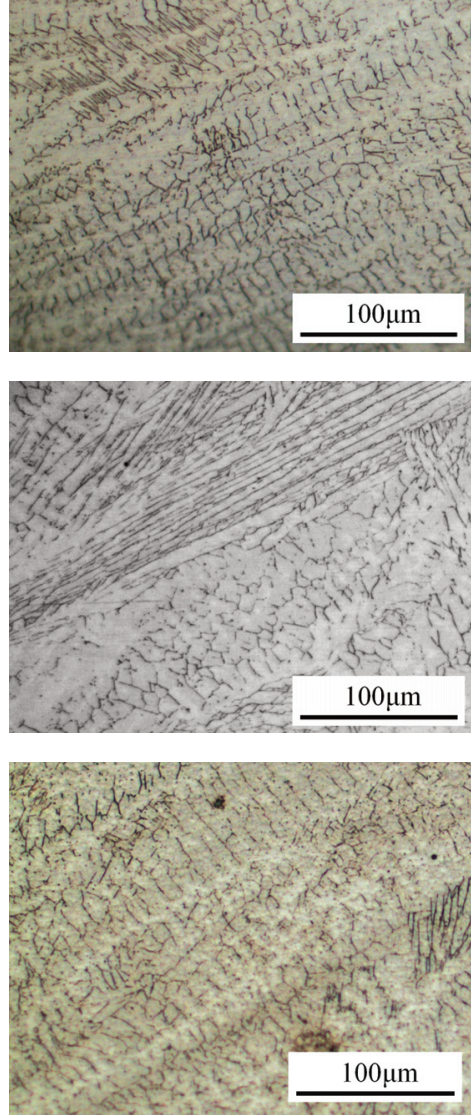

Equiaxed Grain Zone
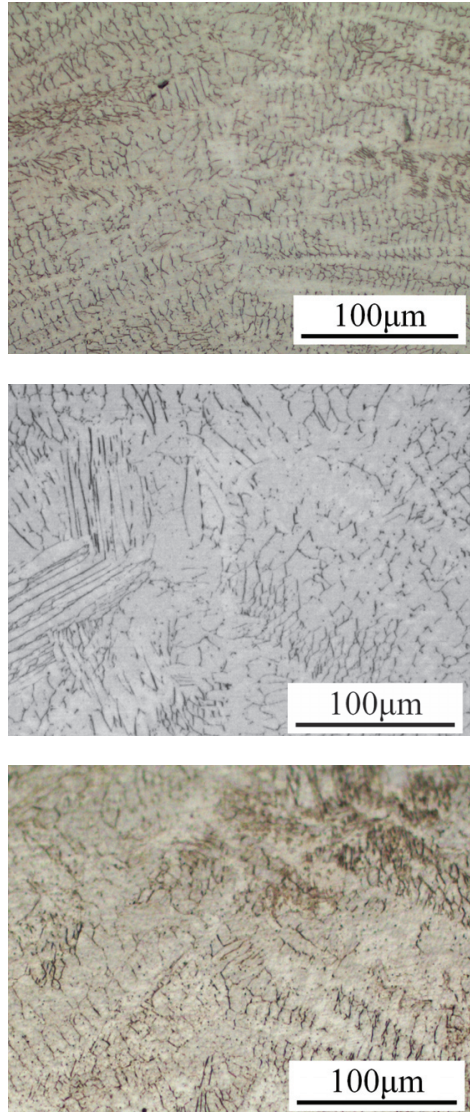
$\mathbf{A}$

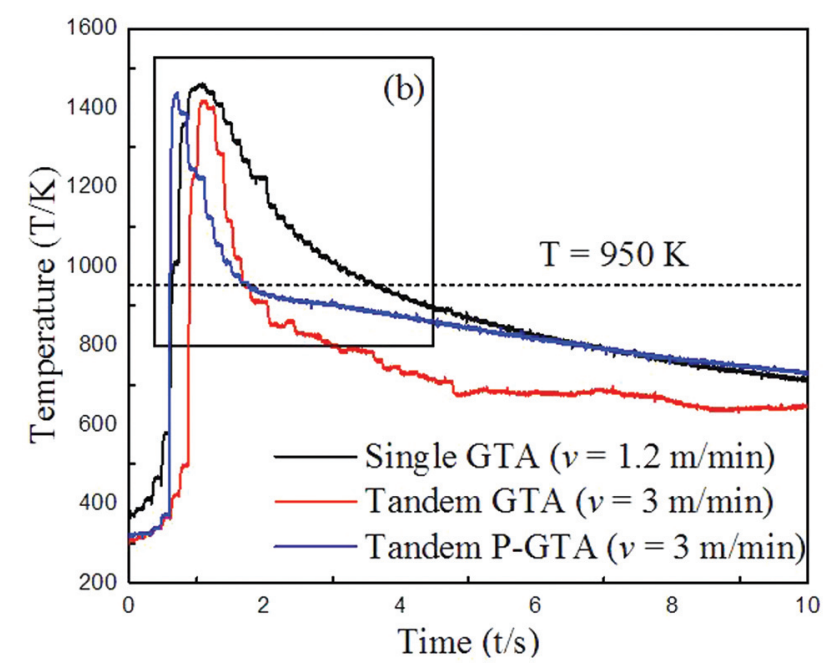

B

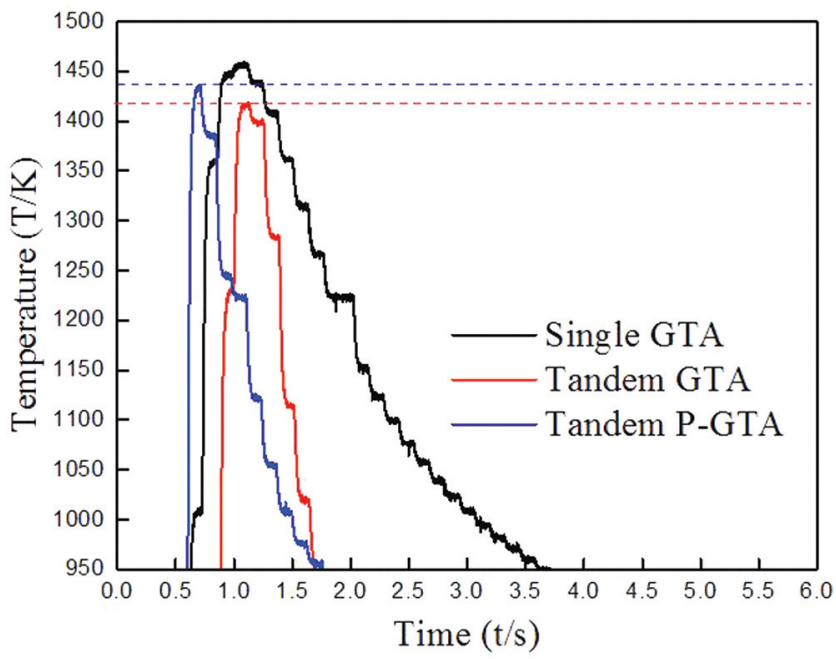

Fig. 11 - Comparison of thermal circles of HAZ on the weld front: A - Thermal circles of HAZ on the top surface; B - thermal circles of partial enlargement.

Meng et al. suggested undercut formation was promoted by the premature solidification of the thin liquid layer at the molten metal periphery, and the instant solidification of the lateral channel at the middle region was the dominant reason for the complete joint penetration humping formation in high-speed GTAW (Refs. 28-30). In highspeed tandem GTAW-P, the assisting arc pulse peak current heated the trailing region of the molten pool to prolong the existence time of the molten metal and to ensure molten metal reflow. Moreover, it significantly suppressed the transverse flow of liquid metal to the centerline at the trailing region of the weld pool and prevented the periphery molten metal from premature solidification, as shown in Fig. 5; thus, a weld appearance without undercut and humping defects would finally be obtained. Furthermore, a higher pulse frequency would increase the depth/width ratio of undercut, whereas the assisting arc duty cycle was the least influential factor.

\section{Properties of Welded Joint}

The weld morphology, microstructure, mechanical properties, and welding heat input of the tandem GTA-P weld were analyzed and compared with those of the tandem GTA and single GTA weld.

Table 6 - Comparison of Tensile Properties of Welds

Nonstandard Specimens

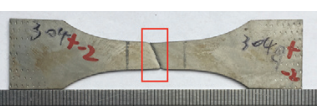

Base Metal

Single GTA

Tandem GTA
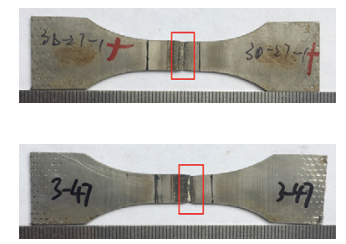

Tandem P-GTA

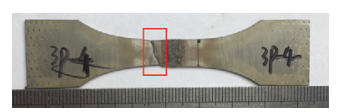

Tensile Strength

$\sigma_{b} / \mathrm{MPa} /$

standard deviation $\sigma_{\mathrm{t}}$
Elongation $\delta / \% /$

standard

deviation $\sigma_{e}$
Fracture

Position

590.8 / 4.1

$65 / 5$

$562.3 / 7$

48.7 / 2.5

Weld toe

586.2 / 3.9

$60 / 5.7$

Weld toe

593.7 / 3.8

57.7 / 2.5

Base metal 

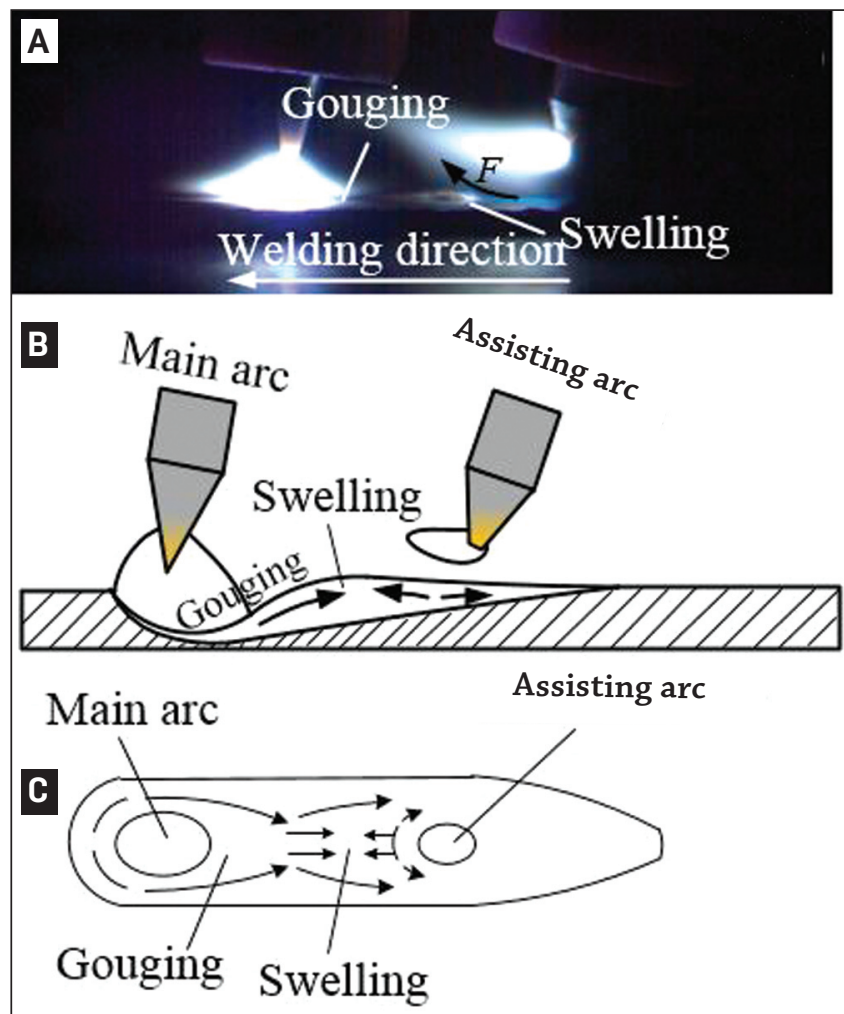

Fig. 12 - Molten pool behavior with main arc current at peak stage and assisting arc current at background stage: A Arc shapes; $B$ - metal flow at the longitudinal section; $C-$ metal flow on the surface of molten pool.

\section{Weld Morphology}

According to the effects of pulse welding current parameters on weld appearance obtained from the orthogonal experiment and further optimization, a sound and completely penetrated weld bead, without undercut and humping defects, was achieved by tandem GTAW-P at a welding speed of $3 \mathrm{~m} / \mathrm{min}$, as shown in Fig. $6 \mathrm{C}$, which demonstrated the feasibility of this process. A comparison of the typical weld appearance of the single GTA and tandem GTA with optimized parameters at different welding speeds is presented in Fig. $6 \mathrm{~A}$ and $\mathrm{B}$. The metallographic diagram of the transverse section of the weld shows the weld front width of the tandem GTA-P is much smaller than that of the tandem GTA, and it is similar to that of the single GTA.

\section{Microstructure}

Figure 7 shows a comparison of microstructure morphology between the single GTA, tandem GTA, and tandem GTA-P welds. The weld zone was divided into two parts based on grain morphology: columnar dendrite grain zone and equiaxed dendrite grain zone. The growth direction of columnar dendrites was extended from the weld interface to the weld centerline in the single GTA weld, and the mean horizontal angle of dendrite growth was $18.97 \mathrm{deg}$. Compared with the traditional single GTA weld, the growth direction of dendrites was extended from the weld interface to

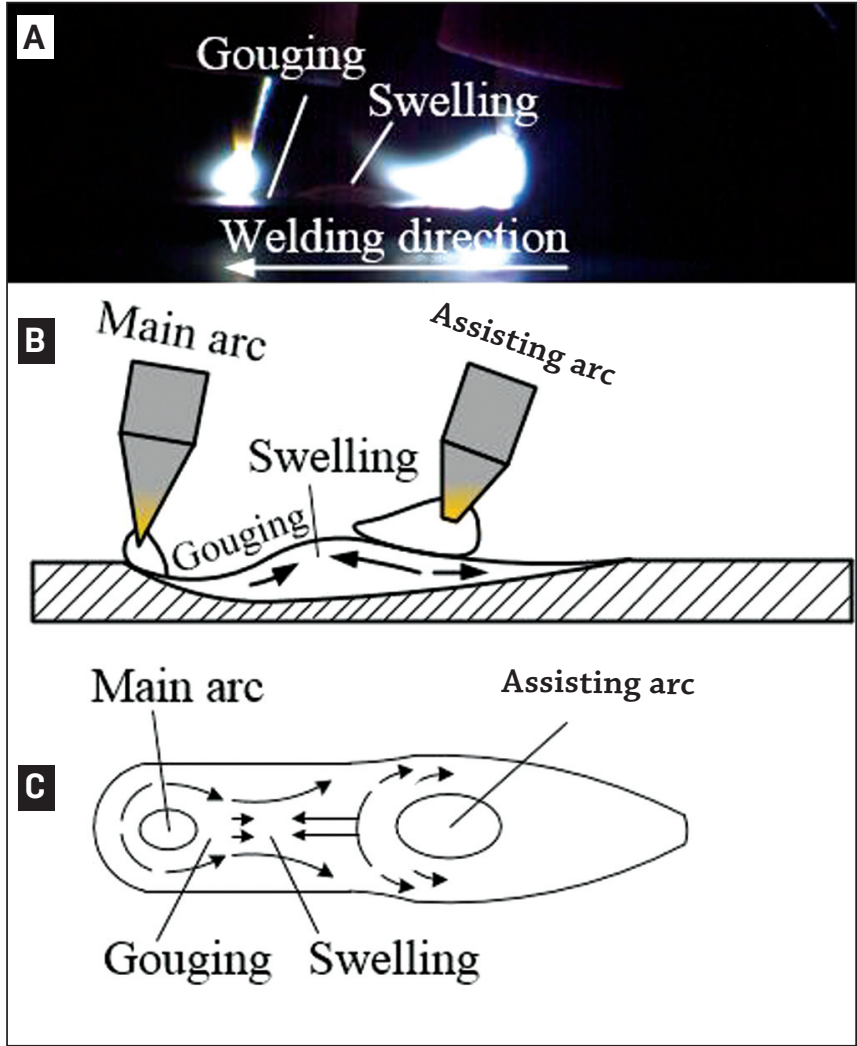

Fig. 13 - Molten pool behavior with main arc current at background stage and assisting arc current at peak stage: A Arc shapes; $B$ - metal flow at the longitudinal section; $C-$ metal flow on the surface of molten pool.

the top of the weld centerline in tandem GTA-P and tandem GTA welds, and the mean horizontal angles of columnar dendrites of these two processes were 33.15 and $33.92 \mathrm{deg}$, respectively. The interpretation of the larger horizontal angle of columnar dendrite growth direction in tandem GTA-P and tandem GTA welds can be that the direction of the temperature gradient was changed by the common effect of the two arcs, which had lower arc pressure than that in the single GTA weld, and was caused by the blunt assisting electrode and the deflection of the two arcs (Refs. 24, 31-33). Correspondingly, much of the arc heat was concentrated on the top of the molten pool, and thus, the columnar dendrite growth directions of the tandem GTA-P and tandem GTA welds were larger than that of the single GTA weld (Ref. 34).

The microstructure of different joint zones of single GTA, tandem GTA, and tandem GTA-P welds were compared, as presented in Table 5. The average grain size in the heataffected zone (HAZ) of the single GTA joint was $20.3 \mu \mathrm{m}$ and that of the tandem GTA joint was $18.2 \mu \mathrm{m}$ measured by the linear intercept method, whereas that of the tandem GTA-P joint was $20.0 \mu \mathrm{m}$. The interdendrite spacing in the molten pool of the tandem GTA-P was $9.4 \mu \mathrm{m}$, and this value was larger than that in the single GTA, with $8.5 \mu \mathrm{m}$, and lower than the one in the tandem GTA, with $11.4 \mu \mathrm{m}$. This increasing interdendrite spacing in tandem GTA and tandem GTA-P was attributed to the fact that cooling rate was slower than in the single GTA owing to the longer existence time of high temperature in the weld center, which provided am- 
ple time for increase in interdendrite spacing, and correspondingly, the dendrites grew farther into the top of the molten pool (Refs. 17, 35). The average grain size in the weld center of the single GTA joint was $12.4 \mu \mathrm{m}$, whereas that of the tandem GTA joint was $14.0 \mu \mathrm{m}$ and that of tandem GTA-P joint was $13.6 \mu \mathrm{m}$. Compared with the tandem GTA weld, the average grain size of the tandem GTA-P weld was relatively smaller.

\section{Mechanical Properties}

To reflect the real values of tensile strength and elongation of welds, nonstandard tensile test specimens were used to detect the tensile properties of the weld, and the tensile test rate was $50 \mathrm{~mm} / \mathrm{min}$. The result value is the average of the values obtained in three tensile specimens with the same welding process, as presented in Table 6 . The fracture positions of the tandem GTA-P nonstandard specimens were not at the weld toe, as in the single GTA and tandem GTA specimens, but at the base metal. The tensile strength of the tandem GTA-P weld was slightly higher than in single GTA and tandem GTA welds, and similar to that in the base metal, but the elongation was smaller than that in the base metal. Moreover, the standard deviation of the tensile properties with three tensile specimens in different welding processes were compared, the discrete degree of tensile properties of the tandem GTA-P weld was relatively lesser than that of single GTA and tandem GTA welds.

The microhardness distribution in single GTA, tandem GTA, and tandem GTA-P joints was analyzed, as shown in Fig. 8. The joints obtained by these three different processes had similar microhardness distribution in both trend and value, and the microhardness in the weld zone and HAZ was higher than in the base metal. Although the microhardness of the tandem GTA-P joint was slightly lower than in single GTA and tandem GTA joints in the weld and fusion zones, the differences in the joint microhardness distribution of the three welding processes were generally similar in the different zones.

\section{Evaluation of Welding Heat Input}

In this study, welding energy consumption was used to evaluate the welding heat input of three different welding processes. The corresponding electrical parameters of the optimized weld bead under these different welding processes were detected by a data acquisition system. The welding energy consumption can be realized by the amount of heat

absorbed per unit length of a weld from a moving heat source as follows:

$$
E=\frac{\sum_{1}^{n} u_{i} I_{i}}{n \cdot v}(i=1,2,3 \ldots n)
$$

where $E$ is the amount of heat absorbed per unit length of a weld, $U_{i}$ is the arc voltage from number $i, I_{i}$ is the welding current from number $i, v$ is the welding speed, and $n$ is the sample size.

To compare the welding energy consumption in a more intuitive and clear way, the welding energy consumption during a single pulse period (1/60 s) was compared, given that the optimized weld bead of the tandem GTA-P was obtained under the condition that both current pulse frequencies were $60 \mathrm{~Hz}$. According to the detection results of electrical parameters of the optimized welds under different welding processes, single pulse period welding power were obtained, as shown in Fig. 9. The average power was obtained by the detection of electrical parameters, the single GTAW was $2552 \mathrm{~W}$, the tandem GTA were 4607 and $1545 \mathrm{~W}$, and the tandem GTA-P were 3212 and $2051 \mathrm{~W}$, respectively. Therefore, the welding energy consumptions were finally obtained. The tandem GTAW-P process was the lowest in the three welding processes, as shown in Fig. 10. The tandem GTAW-P energy consumption was decreased by 17.5 and $14.5 \%$ compared with the single and tandem GTAW, respectively, and it achieved low energy consumption and high efficiency GTAW on a thin-walled stainless steel plate.

\section{Discussion}

\section{Thermal Process of Welding HAZ}

The HAZ temperature on the top of the weld bead was detected by a thermocouple, and is shown in Fig. 11. To prevent the thermocouple from melting, the positions of the temperature measuring point were settled on the HAZ top surface at approximately $1.5 \mathrm{~mm}$ from the weld interface. In addition, given the significant tendency of temperature drop, the setting temperature of $950 \mathrm{~K}$ aimed to obtain a clearer comparison between the three processes. Based on the above method, the cooling rates of different HAZs were obtained from the peak temperature to $950 \mathrm{~K}$. The experimental results show the HAZ cooling rate of the tandem GTA-P was approximately $456.4 \mathrm{~K} / \mathrm{s}$, and it was higher than that of the single GTA, which was approximately $199.9 \mathrm{~K} / \mathrm{s}$. The longer existence time of high temperature, caused by the lower cooling rate, would encourage further grain growth, and correspondingly, the size of the HAZ grain of the single GTA was larger than that of the tandem GTA-P joint. The HAZ cooling rate of the tandem GTA-P was lower than that of the tandem GTA, which was approximately $807.1 \mathrm{~K} / \mathrm{s}$, and the size of the HAZ grain of the tandem GTA-P was larger than that of the tandem GTA, as listed in Table 5. In summary, the HAZ cooling rate of the tandem GTA-P was relatively low; thus, a good HAZ property can be obtained by the tandem GTAW-P welding process.

\section{Weld Pool Behavior}

The flow behavior of the molten metal played an important role in suppressing the formation of undercut and humping defects in the tandem GTAW-P process. The main arc at the peak stage aimed to get sufficient penetration but pushed the molten metal backward. Meanwhile, the assisting arc kept burning at a low current level, which would reduce the unnecessary welding heat input. In tandem GTAW, the two arcs were deflected by electromagnetic attraction as the two electrodes had the same polarity, especially at a small interelectrode distance (Ref. 17). The interaction between the two arcs also existed in tandem GTAW-P, al- 
though the two arc pulse currents were not at their peak stages at the same time. Figure 12A shows that the assisting arc deflected to the main arc severely with the electromagnetic attraction. This feature can be explained by the poorer stiffness of the assisting arc, which was probably caused by the truncated electrode tip with bigger tip angle, the assisting electrode with smaller pushing angle, and the lower current level. Meng et al. suggested the undercut defect would be generated by the elongated, teardrop-shaped molten pool during high-current and high-speed GTAW (Ref. 28). In tandem GTAW-P, the main arc with high current produced a larger arc force that pushed the molten metal to the rear of the molten pool, and a deeper gouging region was formed. Meanwhile, the assisting arc produced a small arc force $(F)$ that promoted the molten metal backward along the center axis line, and correspondingly, reduced the tendency to an undercut defect, as shown in Fig. 12B and C. Additionally, a smaller swelling was formed under the action of the assisting arc. It indicated that the molten metal backward flow was slightly suppressed by the assisting arc, which had a significant deflection caused by electromagnetic attraction between the two arcs.

Usually, the maximum backward velocity of the liquid metal can reach up to $0.6 \mathrm{~m} / \mathrm{s}$ at high-speed GTAW, and the undercut is easily formed by the increasing depression and inward velocity on the molten pool free surface (Ref. 28). The liquid metal requires approximately $0.03 \mathrm{~s}$ to flow from the front region of the molten pool to the trailing part. Considering the frequency of $60 \mathrm{~Hz}$ used in the study, the mainarc current changed into pulse current background and the assisting arc current changed into pulse peak stage before the liquid metal reached the trailing part. Therefore, the depth of the gouging region was decreased by decreasing the main arc force (main current) and increasing the assistingarc force (assisting current), and the depression on the free surface was decreased. Moreover, the main arc produced a smaller force to push the molten metal backward in the pulse current background stage, and the rate of molten metal backward flow was decreased. An assisting arc with a much larger forward arc force promoted the molten metal to flow forward to the leading region of the molten pool, decreased the inward velocity on the molten pool free surface, and correspondingly, facilitated full transverse spreading of the molten pool, as shown in Fig. 13A and C. Furthermore, the action of the assisting arc with pulse peak current could reduce the length of the gouging region and suppress the formation of the humping defect, which could be formed with the elongation of the gouging region in high-speed GTA welding (Refs. 29, 30).

In addition, a larger swelling was formed by the interaction of the two arcs, as shown in Fig. 13A, and a small part of the molten metal between the two arcs flowed transversely, turning around the assisting arc, which also made the weld bead wider, as illustrated in Fig. 13C.

\section{Conclusions}

The tandem GTAW-P process was proposed, and a sound appearance of the weld was obtained. Compared with single and tandem GTA welded joints, the mechanical properties and microstructure of three different weld joints were stud- ied. The tandem GTAW-P mechanism was discussed. The conclusions are summarized as follows:

1) Regarding the width of the weld front, the assisting arc pulse peak current was the most influential factor. The weld width increased with the main arc pulse peak current. For the weld penetration, the main arc current duty cycle was the most influential factor. For the depth/width ratio of undercut, a higher assisting arc pulse peak current tended to obtain a lower depth/width ratio of undercut, and a higher frequency would improve the depth/width ratio of undercut.

2) The welding speed can reach up to $3.0 \mathrm{~m} / \mathrm{min}$ during tandem GTAW-P of a 1.2-mm-thick 304 austenite stainless steel plate, and a sound and completely penetrated weld was achieved, without weld defects.

3) The growth direction of dendrites was extended from the weld interface to the top of the weld centerline, with the mean horizontal angle of $33.15 \mathrm{deg}$. The average grain size in the center of the tandem GTAW-P weld was relatively smaller than that in the tandem GTA weld. Good mechanical properties of the welded joint were obtained by tandem GTAW-P. The welding heat input of the tandem GTA-P was decreased by 17.5 and $14.5 \%$, respectively, compared with those of the single and tandem GTA processes.

4) The HAZ cooling rate of the tandem GTA-P was relatively low; thus, a good HAZ property can be obtained by tandem GTAW-P. When the main arc was at pulse peak, the assisting arc severely deflected to the main arc and the backward flow of molten metal was slightly suppressed. When the main arc was at pulse background, the assisting arc reached pulse peak. The depth of the gouging region decreased by decreasing the main arc force (main current) and increasing the assisting arc force (assisting current). An assisting arc with larger forward arc force decreased the inward velocity on the molten pool free surface and facilitated full transverse spreading of the molten pool.

\section{Acknowledgment}

The authors would like to thank the National Natural Science Foundation of China (Grant No. 51575317) and the Project of Key Research and Development Plan in Shandong Province (Grant No. 2018GGX103033) for their financial support.

\section{References}

1. Bradstreet, B. 1968. Effect of surface tension and metal flow on weld bead formation. Welding Journal 47(7): 314-s to 322-s.

2. Chern, T. S., Tseng, K. H., and Tsai, H. L. 2011. Study of the characteristics of duplex stainless steel activated tungsten inert gas welds. Materials \& Design 32(1): 255-263. DOI: 10.1016/j.matdes.2010.05.056

3. Tseng, K. H., and Hsu, C. Y. 2011. Performance of activated TIG process in austenitic stainless steel welds. Journal of Materials Processing Technology 211(3): 503-512. DOI: 10.1016/j.jmatprotec. 2010.11.003

4. Vidyarthy, R. S., and Dwivedi, D. K. 2016. Activating flux tungsten inert gas welding for enhanced weld penetration. Journal of Manufacturing Processes 22(4): 211-228. DOI: 10.1016/j.jmapro. 2016.03.012 
5. Brown, D. C. 1962. The effect of electromagnetic stirring and mechanical vibration. Welding Journal 41(6): 241-s to 250-s.

6. Lampson, G. L. 1970. Magnetic control of a welding arc. U.S. Patent 3,551,637. 1970-12-29.

7. Jayarjan, T. N., and Jackson, C. E. 1972. Magnetic control of gas tungsten-arc welding process. Welding Journal 51(8): 377-s to 358-s.

8. Nomura, K., Ogino, Y., and Hirata, Y. 2012. Shape control of TIG arc plasma by cusp-type magnetic field with permanent magnet. Welding International 26(10): 759-764. DOI: 10.1080/ 09507116.2011.592691

9. Chang, Y., Yang, D., and Wei, L. 2011. Influence of transverse magnetic on weld appearance in high-speed TIG welding. Transactions of the China Welding Institution 32(3): 49-52.

10. Steen, W. M. 1980. Arc augmented laser processing of materials. Journal of Applied Physics 51(11): 5636-5641. DOI: 10.1063/1.327560

11. Yan, J., Gao, M., and Zeng, X. 2010. Study on microstructure and mechanical properties of 304 stainless steel joints by TIG, laser and laser-TIG hybrid welding. Optics and Lasers in Engineering 48(4): 512-517. DOI: 10.1016/j.optlaseng.2009.08.009

12. Ono, M., Shinbo, Y., and Yoshitake, A. 2002. Development of laser-arc hybrid welding. Nkk Technical Report-Japanese Edition No. 86: 8-12.

13. Dilthey, U., and Wiesschemann, A. 2002. Perspectives offered by combining a laser beam with arc welding procedures. Welding International 16(9): 711-719. DOI: 10.1080/ 09507110209549601

14. Kobayashi, K., Nishimura, Y., and Iijima, T. 2004. Practical application of high efficiency twin-arc TIG welding method (SEDAR-TIG) for PCLNG storage tank. Welding in the World 48(7-8): 35-39. DOI: 10.1007/BF03266441

15. Lin, M. L., and Eagar, T. W. 1985. Influence of arc pressure on weld pool geometry. Welding Journal 64(6): 163-s to 169-s.

16. Leng, X. S., Zhang, G. J., and Wu, L. 2006. Experimental study on improving welding efficiency of twin electrode TIG welding method. Science and Technology of Welding and Joining 11(5): 550-554. DOI: 10.1179/174329306X122785

17. Qin, G., Meng, X., and Fu, B. 2015. High speed tandem gas tungsten arc welding process of thin stainless steel plate. Journal of Materials Processing Technology 220(1): 58-64. DOI: 10.1016/j. jmatprotec.2015.01.011

18. Qin, G., Meng, X., and Fu, B. 2015. High speed tandem TIG welding of thin-walled stainless steel pipe. Journal of Mechanical Engineering 51(12): 83-88. DOI: 10.3901/JME.2015.12.083

19. Ghosh, P. K., Dorn, L., Kulkarni, S. et al. 2009. Arc characteristics and behaviour of metal transfer in pulsed current GMA welding of stainless steel. Journal of Materials Processing Technology 209(3): 1262-1274. DOI: 1016/j.jmatprotec.2008.03.049

20. Liu, Q. 2012. A study on the small current pulsed TIG welding power source and the arc physical characteristics. PhD dissertation. Beijing University of Technology.

21. Cook, G. E., and Eassa, H. E. 1985. The effect of high-frequency pulsing of a welding arc. IEEE Transactions on Industry Applications 5: 1294-1299. DOI: 10.1109/TIA.1985.349557

22. Shi, Y., Guo, C., Huang, J., et al. 2011. Numerical simulation of pulsed current tungsten inert gas (TIG) welding arc. Acta Physica Sinica 60(4): 0481021-0481027.

23. Rokhlin, S. I., and Guu, A. C. 1993. A study of arc force, pool depression, and weld penetration during gas tungsten arc welding. Welding Journal 72(8): 381-s to 389-s.

24. Wu, K., Wang, J., Yin, T., et al. 2018. Double arc interference and dynamic behavior characteristics of double wire double-pulsed GMAW. The International Journal of Advanced Manufacturing Technology 95: 991-1002. DOI: 10.1007/s0017

25. Chen, D., Chen, M., and Wu, C. 2015. Effects of phase difference on the behavior of arc and weld pool in tandem P-GMAW. Journal of Materials Processing Technology 225: 45-55. DOI: 10.1016/j.jmatprotec.2015.05.022

26. Reis, R. P., Souza, D., and Ferreira, F. D. 2015. Arc interruptions in tandem pulsed gas metal arc welding. Journal of Manufacturing Science and Engineering 137(011004): 1-10. DOI: 10.1115/ 1.4028681

27. Schwedersky, M. B., Gonçalves e Silva, R. H., Dutra, J. C., et al. 2016. Two-dimensional arc stagnation pressure measurements for the double-electrode GTAW process. Science and Technology of Welding and Joining 21(4): 275-280. DOI: 10.1080/13621718. 2015.1104095

28. Meng, X., Qin, G., and Bai, X. 2016. Numerical analysis of undercut defect mechanism in high speed gas tungsten arc welding. Journal of Materials Processing Technology 236: 225-234. DOI: 10.1016/j.jmatprotec.2016.05.020

29. Meng, X., Qin, G., and Zou, Z. 2016. Investigation of humping defect in high speed gas tungsten arc welding by numerical modelling. Materials \& Design 94: 69-78. DOI: 10.1016/ j.matdes.2016.01.019

30. Meng, X., Qin, G., and Bai, X. 2016. Humping phenomena in high-speed GTAW of different weld penetrations. Welding Journal 95(9): 331-s to 339-s. DOI: 10.1016/j.jmatprotec.2015.01.011

31. Ding, X., Li, H., Wei, H., et al. 2016. Numerical analysis of arc plasma behavior in double-wire GMAW. Vacuum 124: 46-54. DOI: doi.org/10.1016/j.vacuum.2015.11.006

32. Meng, X., Qin, G., and Zou, Z. 2017. Sensitivity of driving forces on molten pool behavior and defect formation in high-speed gas tungsten arc welding. International Journal of Heat and Mass Transfer 107: 1119-1128. DOI: 10.1016/j.ijheatmasstransfer. 2016.11.025

33. Meng, X., Qin, G., and Zhang, Y. 2014. High speed TIGMAG hybrid arc welding of mild steel plate. Journal of Materials Processing Technology 214(11): 2417-2424. DOI: 10.1016/ j.jmatprotec.2014.05.020

34. Jiang, H., Qin G., Feng C., et al. 2019. Microstructure and properties of weld by high-speed tandem TIG welding of thin 304 stainless steel plate. Transactions of the China Welding Institution. 40(1): 015-018. DOI: 10.12073/j.hjxb.2019400004

35. Chuaiphan, W., and Loeshpahn, S. 2014. Effect of welding speed on microstructures, mechanical properties and corrosion behavior of GTA-welded AISI 201 stainless steel sheets. Journal of Materials Processing Technology 214(2): 402-408. DOI: 10.1016/j.jmatprotec.2013.09.025

HAIHONG JIANG, GUOLIANG QIN (glqin@sdu.edu.cn), CHAO FENG, and XIANGMENG MENG are with Key Laboratory for LiquidSolid Structural Evolution and Processing of Materials, Minisitry of Education, Shandong University, Jinan, China. 